\title{
Adenovirus Activates Complement by Distinctly Different Mechanisms In Vitro and In Vivo: Indirect Complement Activation by Virions In Vivo $\nabla$
}

\author{
Jie Tian, ${ }^{1} \dagger$ Zhili Xu, ${ }^{1} \dagger$ Jeffrey S. Smith, ${ }^{1}$ Sean E. Hofherr, ${ }^{2}$ \\ Michael A. Barry, ${ }^{2,3}$ and Andrew P. Byrnes ${ }^{1 *}$ \\ Division of Cellular and Gene Therapies, Center for Biologics Evaluation and Research, Food and Drug Administration, Bethesda, \\ Maryland, ${ }^{1}$ and Department of Internal Medicine, ${ }^{2}$ Division of Infectious Diseases, Translational Immunovirology Program, \\ Department of Immunology and Department of Molecular Medicine, ${ }^{3}$ Mayo Clinic, Rochester, Minnesota
}

Received 13 January 2009/Accepted 19 March 2009

\begin{abstract}
Understanding innate immunity is key to improving the safety of adenovirus (Ad) vectors for systemic gene therapy. Ad has been shown to activate complement in vitro, but activation of complement after Ad injection in vivo has not been directly measured. Using complement protein C3a as a marker of complement activation, we show that types 2 and 5 human Ads cause rapid complement activation after intravenous injection in mice. Unexpectedly, the mechanisms in vivo were different than those in vitro. Antibodies were critical for the activation of complement by Ad in vitro, but antibodies were not required in vivo. The classical pathway was required in vitro, whereas complement activation in vivo involved both classical and nonclassical pathways as well as the reticuloendothelial system. Remarkably, the entrydeficient Ad mutant ts 1 was completely unable to activate complement in vivo even though it was fully able to activate complement in vitro. This result demonstrates that the complement system senses intravenously injected Ad primarily by detecting the effects of Ad on cells rather than through direct interaction of complement with virions. Encouragingly, shielding Ad with polyethylene glycol was effective at reducing complement activation both in vitro and in vivo. In summary, intravenously injected Ad rapidly activates complement through multiple pathways, but these pathways are different than those identified by in vitro studies. In vitro studies are poorly predictive of in vivo mechanisms because Ad virions activate complement through indirect mechanisms in vivo.
\end{abstract}

Innate immune responses have proven to be one of the most significant and difficult barriers to safe systemic gene therapy with adenovirus (Ad) vectors (20). Systemic intravascular (i.v.) delivery of nonreplicating Ad vectors induces a number of potentially dangerous responses within minutes to hours, including the production of cytokines and chemokines, coagulopathy, hemodynamic changes, liver damage, and thrombocytopenia $(39,54,55,68)$. These responses are triggered by multiple innate mechanisms that respond to various features of Ad vectors. Much of the cytokine response is initiated by innate pattern recognition proteins, such as TLR9, which can recognize Ad genomic DNA (4, 8, 42, 45, 69). Phagocytic cells in the liver and spleen also play an important role in the innate response to systemically delivered Ad vectors (4, 37, 38, 54, 56, 68). Likewise, complement is an ancient innate defense system that detects and responds to pathogens, including viruses (52). It is well established that complement plays a major role in the innate response against Ad (30), but the mechanisms through which Ad interacts with complement in vivo are currently unknown.

A number of previous reports have demonstrated that

\footnotetext{
* Corresponding author. Mailing address: Division of Cellular and Gene Therapies, FDA CBER, HFM-725, 8800 Rockville Pike, Bethesda, MD 20892. Phone: (301) 827-1786. Fax: (301) 827-0449. E-mail: Andrew.Byrnes@fda.hhs.gov.

$\dagger$ J.T. and Z.X. contributed equally to this work.

${ }^{\nabla}$ Published ahead of print on 25 March 2009.
}

complement is activated when Ad is mixed with human plasma in vitro $(2,9,29,49,67)$. Most humans have been infected with multiple Ad serotypes; therefore, human plasma typically contains antibodies that recognize Ad. Because of this, antibody-mediated initiation of the classical pathway plays a major role in complement activation by Ad in vitro $(9,49,67)$. During the process of complement activation in vitro, Ad becomes opsonized by complement proteins, such as $\mathrm{C} 3$ and $\mathrm{C} 4(7,66)$, and complement-opsonized Ad can be recognized by complement receptors on cells, leading to cellular uptake $(7,10,62)$. Because of the importance of complement in innate immunity, pathogens frequently use strategies to interfere with or evade complement (36). In this regard, it is interesting that although human Ad5 activates complement well, canine Ad type 2 possesses complement-inhibitory properties (49).

The in vitro studies described above were performed with the expectation that they would provide insights into how Ad interacts with complement in vivo. However, to the best of our knowledge, the extent to which Ad activates complement in vivo has not previously been measured in clinical studies or in animal studies. Nevertheless, one can infer that complement must be activated after injection of Ad, because complementdeficient $\mathrm{C} 3$ knockout (KO) mice show greatly attenuated innate responses after the systemic delivery of Ad vectors, including reduced cytokine levels and less thrombocytopenia (2, $3,21,30)$. In addition, complement helps to shape the adaptive immune response and influences the isotype distribution of 
antibody responses to Ad vectors (3). Complement can also affect liver transduction by Ad vectors and uptake of Ad by Kupffer cells (KCs) in the liver, although only to a modest degree $(66,70)$.

In order to learn more about how Ad activates complement in vivo, we investigated the kinetics, dose response, and mechanisms of complement activation after i.v. injection of Ad in mice. We found that complement is rapidly activated after $\mathrm{Ad}$ injection, even at doses of Ad that are too low to cause substantial activation of other innate responses. Unexpectedly, we discovered that the mechanisms for complement activation are completely different in vitro and in vivo, demonstrating the limitations of in vitro experiments as models for complex in vivo phenomena. We found that Ad-induced cell damage was the most important stimulus for complement activation in vivo, rather than direct recognition of virions by the complement system.

\section{MATERIALS AND METHODS}

Ad viruses and vectors. Replication-defective human Ad5 vectors with $\mathrm{E} 1$ and E3 deleted, expressing nuclear-localized $\beta$-galactosidase (Av1nBg, S*, 35S5H), cytoplasmic $\beta$-galactosidase (AdCB2), firefly luciferase (AdLuc), or green fluorescent protein (AdGFP) were grown and purified by $\mathrm{CsCl}$ density gradient ultracentrifugation as described previously $(58,59)$. Ad vector particle (vp) concentrations were measured spectrophotometrically, with no detectable aggregation, as described previously (58). Infectivity was measured as PFU on 293 cells. The Ad mutant $t s 1$ was grown at $39^{\circ} \mathrm{C}$ as previously described (59), and wild-type human $\mathrm{Ad} 2$ was used as a control. The particle-to-PFU ratio of the $t s 1$ mutant (measured at $33^{\circ} \mathrm{C}$ ) was more than 200 -fold higher than that of $\mathrm{Ad} 2$, indicating that the vast majority of virions in the $39^{\circ} \mathrm{C} t s 1$ mutant preparation were noninfectious, as expected. Vectors and viruses were prepared in a buffer of $2.5 \%$ glycerol, $25 \mathrm{mM} \mathrm{NaCl}$, and $20 \mathrm{mM}$ Tris ( $\mathrm{pH} \mathrm{8.0)}$ ), and this buffer was also used for control injections in mice.

PEGylated AdGFP-AdLuc was prepared as previously described $(23,40)$ by covalent conjugation with succinimide-activated $5-\mathrm{kDa}$ polyethylene glycol (PEG) (Sunbright ME-050-HS; NOF, Tokyo, Japan). Control unPEGylated AdGFP-AdLuc was prepared by following exactly the same procedures except that PEG was omitted. For experiments with PEGylated Ad, the buffer was KPBS (150 mM NaCl, $1 \mathrm{mM} \mathrm{MgCl} 2,5 \%$ [wt/vol] sucrose, $10 \mathrm{mM} \mathrm{K}_{2} \mathrm{HPO}_{4}[\mathrm{pH}$ 7.8]). The $\mathrm{vp} /$ milliliter concentrations were determined by quantitative PCR. PEGylation resulted in an increase in the diameter of Ad particles as measured by dynamic light scattering (from $97.2 \mathrm{~nm}$ before PEGylation to $126.5 \mathrm{~nm}$ after PEGylation). PEGylation caused a 3,000-fold increase in the particle-to-PFU ratio on 293 cells, but there was no significant decrease in the ability to transduce the liver in vivo, in agreement with previous results $(23,40)$. Liver luciferase activity was measured as previously described (57).

All vectors, viruses, and solutions were verified to contain $<0.3$ endotoxin units/ml of endotoxin by the Limulus amoebocyte lysate method (Charles River Endosafe, Charleston, SC).

Animals. Animal experiments were approved by the FDA CBER Animal Care and Use Committee. All mice were specific-pathogen-free males on the C57BL/6 background, aged 7 to 11 weeks old. C57BL/6NCr mice from the National Cancer Institute (Frederick, MD) were used for most experiments, and C57BL/6J mice from the Jackson Laboratory (Bar Harbor, ME) were used as controls for $\mathrm{KO}$ mice. No differences were found between results for the two C57BL/6 substrains. Rag-1 KO mice (41) were obtained from the Jackson Laboratory and bred in our facility. $\mathrm{C1q} \mathrm{KO}$ mice, originally produced by Marina Botto (5), were kindly provided on a C57BL/6 background by Michael Diamond (Washington University, St. Louis, MO) and bred in our facility.

All experiments were performed with Ad-naïve mice except where indicated. For immunization, mice were injected intramuscularly with $1.0 \times 10^{10} \mathrm{vp}$ of AdCB2. Two weeks after immunization, mice were either bled for in vitro experiments or challenged i.v. with of AdLuc at $1.0 \times 10^{12} \mathrm{vp} / \mathrm{kg}$ of body weight.

As previously described (59), awake mice were briefly restrained in a cylindrical device for tail vein injections at a volume of $8.0 \mathrm{ml} / \mathrm{kg}$. Shortly before blood was to be drawn, mice were anesthetized by intraperitoneal injection of ketamine and xylazine. After the anesthesia took effect, the thorax was rapidly opened and blood was drawn from the heart.
For in vitro complement protein $\mathrm{C} 3 \mathrm{a}$ generation experiments, the blood was immediately diluted with a 1/10 volume of citrate-dextrose solution (Sigma) and chilled on ice. The plasma was separated in a refrigerated centrifuge and briefly stored on ice before use in experiments.

For studies of the in vivo levels of $\mathrm{C} 3 \mathrm{a}$, the plasma was carefully collected in a manner that avoided undesired ex vivo complement activation. Blood was drawn from the heart and immediately placed into EDTA tubes (BD Biosciences) on ice. In addition, the protease inhibitor Futhan (BD Biosciences) was added at $50 \mu \mathrm{g} / \mathrm{ml}$ to further arrest complement (50). Plasma was separated in a refrigerated centrifuge and stored at $-80^{\circ} \mathrm{C}$ until enzyme-linked immunosorbent assays (ELISAs) were performed.

In vitro complement experiments. Freshly obtained citrate plasma samples were mixed on ice with Ad at a concentration of $5.0 \times 10^{10} \mathrm{vp} / \mathrm{ml}$. This concentration of Ad was chosen based on the work of Cichon et al. (9), who studied complement activation by Ad in human plasma. This concentration also approximates the theoretical peak Ad concentration in mice after an i.v. injection of $1.0 \times 10^{12} \mathrm{vp} / \mathrm{kg}$. In a 25 -g mouse, the peak Ad concentration would be $2.5 \times$ $10^{10} \mathrm{vp} / \mathrm{ml}$, assuming a plasma volume of $1.0 \mathrm{ml}$. In experiments to detect dependency on calcium, we added $10 \mathrm{mM}$ EGTA prior to adding Ad.

After the addition of Ad and gentle mixing on ice, plasma samples were incubated at $37^{\circ} \mathrm{C}$ for $90 \mathrm{~min}$. To stop further complement activation, the samples were placed on ice and $10 \mathrm{mM}$ EDTA and $50 \mu \mathrm{g} / \mathrm{ml}$ Futhan were added. Samples were frozen at $-80^{\circ} \mathrm{C}$ until the ELISA was performed.

Depletion of macrophages. Dichloromethylenediphosphonic acid (clodronate) was obtained from Sigma-Aldrich, Inc. (St. Louis, MO). Liposomes were prepared and loaded with clodronate exactly as described by van Rooijen and Sanders (63). Clodronate liposomes were resuspended in phosphate-buffered saline (PBS), and mice were injected i.v. 1 day in advance with a dose of $10 \mathrm{ml} / \mathrm{kg}$. This is a relatively high dose that depletes phagocytic cells in both the liver and spleen (63). We verified by using immunofluorescence that this treatment caused $100 \%$ depletion of F4/80 antibody-positive KCs in the liver and 50\% depletion of macrophages in the spleen. Control mice were injected i.v. with PBS 1 day in advance.

ELISAs. Plasma levels of anti-Ad immunoglobulin $\mathrm{M}(\operatorname{IgM})$ and $\operatorname{IgG}$ were evaluated by ELISA on Ad-coated plates as previously described (66). Plasma was serially diluted, and the anti-Ad titer was defined as the highest dilution having an optical absorbance of $\geq 0.2$ at $450 \mathrm{~nm}$.

To quantitate mouse C3a levels, 96-well plates were coated with $1 \mu \mathrm{g} / \mathrm{ml}$ of rat anti-mouse C3a clone I87-1162 (BD Biosciences, San Jose, CA) in PBS. After being blocked with $10 \%$ heat-inactivated fetal calf serum in PBS, the plasma samples were added to PBS containing $10 \%$ fetal calf serum, $10 \mathrm{mM}$ EDTA, and $0.05 \%$ Tween 20 (Sigma-Aldrich Inc., St. Louis, MO). A standard curve of purified mouse $\mathrm{C} 3 \mathrm{a}$ (BD Biosciences) was prepared with the same buffer. After an overnight incubation at $4^{\circ} \mathrm{C}$, bound $\mathrm{C} 3$ a was detected with $0.25 \mu \mathrm{g} / \mathrm{ml}$ of biotinylated rat anti-C3a clone I87-419 (BD Biosciences), followed by streptavidin-horseradish peroxidase (BD Biosciences) and tetramethylbenzidine.

Baseline C3a levels in our mouse plasma samples were similar to those previously reported for human samples (50), but significant activation of complement occurred during the 90 -min in vitro experiments even in the absence of virus, leading to much higher baselines. This is because the complement system has a certain amount of activity in vitro even in the absence of exogenous stimuli. C3a levels were found to vary among different experiments, so for each experiment, animals were handled as a group and samples were analyzed together on a single ELISA plate.

Both in vitro and in vivo, the $\mathrm{C}$-terminal Arg residue of $\mathrm{C} 3 \mathrm{a}$ is rapidly removed by the ubiquitous enzyme serum carboxypeptidase $\mathrm{N}$. This results in the formation of C3a-desArg (25). C3a and C3a-desArg are both biologically active but stimulate different receptors and have different activities. The antibodies used in our C3a ELISA react with both C3a and C3a-desArg and do not differentiate between these two forms. Similarly, commercially available ELISAs for human $\mathrm{C} 3 \mathrm{a}$ also fail to differentiate between $\mathrm{C} 3 \mathrm{a}$ and $\mathrm{C} 3 \mathrm{a}$-desArg.

Statistical analysis. In all figures, means \pm standard deviations are shown. Experiments were analyzed by $t$ test or analysis of variance (ANOVA). Post hoc ANOVA group comparisons were performed using the Holm-Sidak test (SigmaPlot 11.0, Systat Software, San Jose CA), with significance defined as a $P$ value of $\leq 0.05$. When necessary, data were log transformed prior to statistical analysis to equalize variances. In a single instance in one group of buffer-injected mice, an outlier ( $P \leq 0.01$, Grubb's test) with nearly threefold-higher-than-normal levels of $\mathrm{C} 3 \mathrm{a}$ was identified and removed from analysis. The removal of this single animal did not change the conclusions of the experiment. 

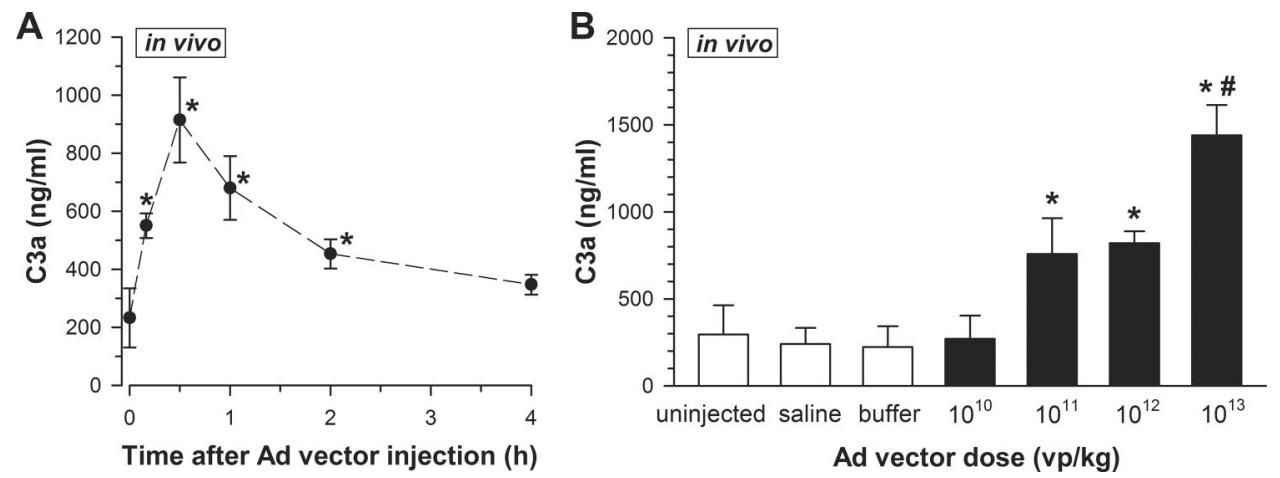

FIG. 1. Tail vein injection of Ad causes activation of complement within $10 \mathrm{~min}$. (A) C57BL/6 mice were injected with Ad vector at a dose of $1.0 \times 10^{12} \mathrm{vp} / \mathrm{kg}$, and groups of three or four mice were sacrificed at various time points. Plasma was collected and assayed for C3a levels by ELISA. $*, P$ value of $\leq 0.05$ versus uninjected mice (Holm-Sidak post hoc). (B) Mice (three or four per group) were injected with increasing doses of the Ad vector, and plasma was collected at $30 \mathrm{~min}$ for C3a determination. Significant elevation of C3a was found at doses of $\geq 1.0 \times 10^{11} \mathrm{vp} / \mathrm{kg}(*$, $P$ value of $\leq 0.05$ versus all control groups). Mice injected with $1.0 \times 10^{13} \mathrm{vp} / \mathrm{kg}$ of the Ad vector had higher plasma C3a levels than at any other dose of Ad (\#, $P$ value of $\leq 0.05$ versus every other group, Holm-Sidak post hoc).

\section{RESULTS}

Ad induces rapid complement activation in vivo. $\mathrm{C} 3$ is a central protein in the complement activation cascade that is activated by all three of the complement initiation pathways: classical, alternative, and lectin (52). Therefore, the total level of complement activity can be assessed by measuring the concentration of $\mathrm{C} 3 \mathrm{a}$, a soluble fragment that is released after $\mathrm{C} 3$ cleavage (25). There have been a number of studies that show that mixing Ad with human plasma causes generation of $\mathrm{C} 3 \mathrm{a}$ $(9,49,67)$, but we are not aware of any studies that have measured the amount of complement activation by Ad in vivo. We therefore measured plasma levels of $\mathrm{C} 3 \mathrm{a}$ in mice after tail vein injection of Ad.

Injecting Ad i.v. at a dose of $1.0 \times 10^{12} \mathrm{vp} / \mathrm{kg}$ caused a rapid increase in plasma $\mathrm{C} 3 \mathrm{a}$ that was statistically significant as soon as 10 min after injection, which was the earliest time point that we examined (Fig. 1A). Plasma concentrations of C3a peaked at $30 \mathrm{~min}$ and declined slowly thereafter. Injection of buffer or saline did not cause any change in plasma C3a levels compared to those in uninjected mice (Fig. 1B). We also examined the dose responsiveness of complement activation at $30 \mathrm{~min}$ postinjection. A dose of $1.0 \times 10^{10} \mathrm{vp} / \mathrm{kg}$ did not detectably activate complement, but doses of $\geq 1.0 \times 10^{11} \mathrm{vp} / \mathrm{kg}$ caused a significant elevation of C3a (Fig. 1B).

Throughout this study, we used a standard Ad dose of $1.0 \times$ $10^{12} \mathrm{vp} / \mathrm{kg}\left(2.5 \times 10^{10} \mathrm{vp}\right.$ for a $25-\mathrm{g}$ mouse $)$, but we also examined the effects of higher or lower doses in selected experiments. A dose of $1.0 \times 10^{12} \mathrm{vp} / \mathrm{kg}$ is quite moderate; it is able to transduce only a small fraction of hepatocytes and causes relatively limited toxicity in mice and nonhuman primates $(6,46,61,68)$. This dose is also similar to the highest dose that has been administered to a human by an i.v. route (53). Most studies of Ad-induced innate immunity are performed with considerably larger amounts of Ad, because a dose of $1.0 \times 10^{12} \mathrm{vp} / \mathrm{kg}$ results in only a slight induction of cytokines, especially in mice $(6,68)$. In light of this, it is interesting that we found that even a 10-fold-lower dose, $1.0 \times 10^{11}$ $\mathrm{vp} / \mathrm{kg}$, was still sufficient to cause significant complement activation in mice (Fig. 1B). Overall, these time course and dose response experiments show that the plasma level of $\mathrm{C} 3 \mathrm{a}$ is an early and extremely sensitive indicator of the innate response to Ad.

Different complement activation pathways in vitro and in vivo. We have previously shown that normal mouse serum contains natural IgM antibodies that bind to Ad and that adding mouse serum to Ad results in opsonization of Ad by $\mathrm{C} 3$ and $\mathrm{C} 4$ in a process that is dependent on calcium and antibodies (66). These results strongly suggest that Ad activates complement via the classical pathway in vitro, wherein initial binding of natural antibodies would be followed by calciumdependent binding of the C1qrs complex and subsequent formation of the $\mathrm{C} 4 \mathrm{~b} 2 \mathrm{a}$ convertase, which cleaves $\mathrm{C} 3$ (52). In the current study, we used $\mathrm{C} 1 \mathrm{q} \mathrm{KO}$ mice that completely lack the classical pathway (5) to definitively determine whether the classical pathway is required for complement activation by $\mathrm{Ad}$ both in vitro and in vivo. We also used antibody-deficient Rag-1 KO mice (41) to determine whether natural antibodies are important.

We found that antibodies and the classical pathway were absolutely required for $\mathrm{C} 3 \mathrm{a}$ generation in vitro; calcium, natural antibodies, and $\mathrm{C} 1 \mathrm{q}$ were all necessary for Ad to activate complement in mouse plasma (Fig. 2A and B). However, when we injected mice i.v. with Ad vectors, we found that natural antibodies played no apparent role in $\mathrm{C} 3$ a production in vivo, with no detectable difference between results for wild-type and Rag-1 KO mice (Fig. 2C). In contrast, the classical pathway played a key role in vivo, because complement activation was significantly lower in $\mathrm{C} 1 \mathrm{q} \mathrm{KO}$ mice than in either wild-type or Rag1 KO mice (Fig. 2C). These results highlight the fact that the initial signals for classical pathway activation are different in vitro and in vivo. Natural antibodies are needed for complement activation in vitro, but not in vivo (Fig. $2 \mathrm{~B}$ and $\mathrm{C}$ ). Although antibody is the best-known initiator of the classical pathway, there are also numerous other nonantibody initiators (15). Our results demonstrate that antibody-independent classical pathway activation is one of the major mechanisms for complement activation by Ad in vivo.

Although Ad caused less complement activation in $\mathrm{C} 1 \mathrm{q} \mathrm{KO}$ mice, it is important to note that Ad was still able to activate complement in $\mathrm{C} 1 \mathrm{q} \mathrm{KO}$ mice to a level that was significantly 

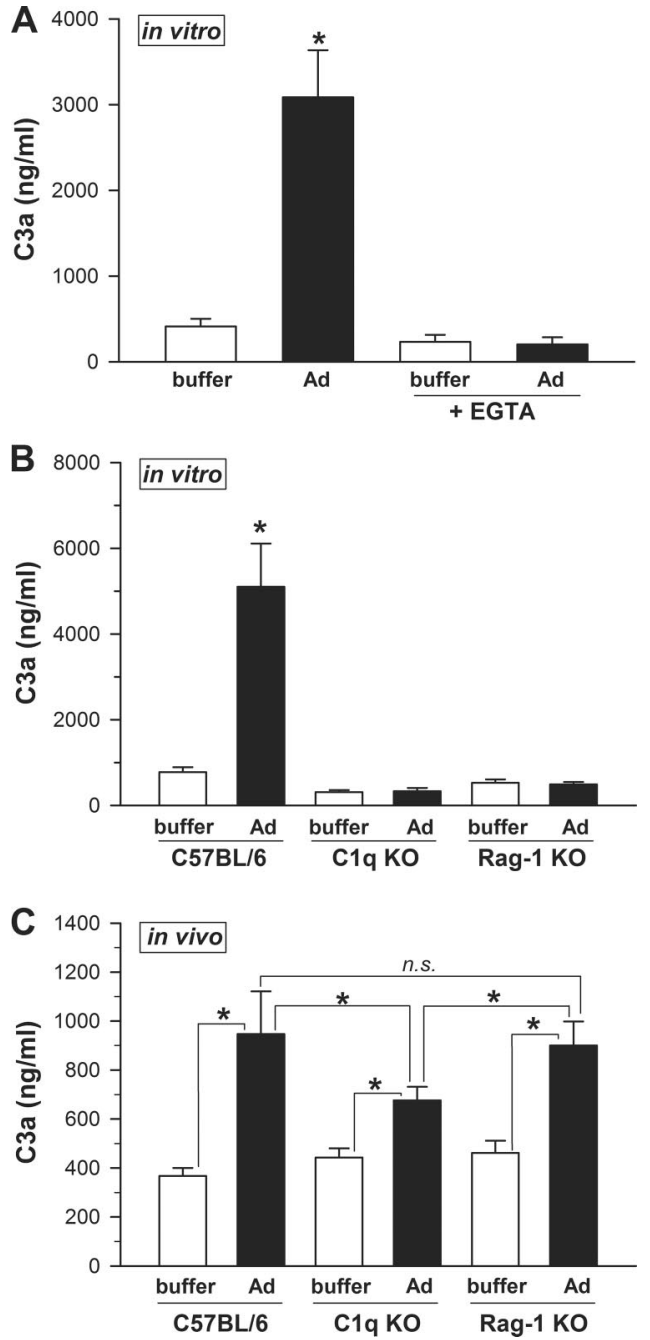

FIG. 2. Ad activates the classical pathway both in vitro and in vivo. Complement activation is antibody dependent in vitro but not in vivo. (A) Complement activation in vitro requires calcium. Mouse plasma (four samples per group) was mixed with buffer or Ad vector $(5.0 \times$ $10^{10} \mathrm{vp} / \mathrm{ml}$ ) in the presence or absence of EGTA to chelate calcium. After a 90 -min incubation at $37^{\circ} \mathrm{C}, \mathrm{C} 3$ a levels were measured. An independent experiment yielded similar results. *, $P$ value of $\leq 0.05$ versus all other groups (Holm-Sidak post hoc). (B) Complement activation in vitro is absolutely dependent on natural antibodies and $\mathrm{C} 1 \mathrm{q}$. Ad was incubated with wild-type mouse plasma, C1q-deficient plasma, or antibody-deficient plasma (Rag-1 KO), with four plasma samples per group. C3a was measured after a 90-min incubation as before. An independent experiment yielded similar results. *, $P$ value of $\leq 0.05$ versus all other groups (Holm-Sidak post hoc). (C) Complement activation in vivo depends in part on $\mathrm{Clq}$, but antibody is not required. Mice (four per group) were injected i.v. with buffer or $1.0 \times 10^{12} \mathrm{vp} / \mathrm{kg}$ of Ad vector. Plasma was collected $30 \mathrm{~min}$ later for C3a ELISA. Similar results were found in an independent experiment. $*, P$ value of $\leq 0.05$ (Holm-Sidak post hoc); n.s., not significant.

above the baseline (Fig. 2C). Thus, both classical (C1q-dependent) and nonclassical (C1q-independent) pathways are involved in the activation of complement by Ad in vivo. Again, this result contrasts with that from the in vitro system, where complement activation is not seen if the classical pathway is absent.

In vitro studies using plasma from Ad-immune humans have
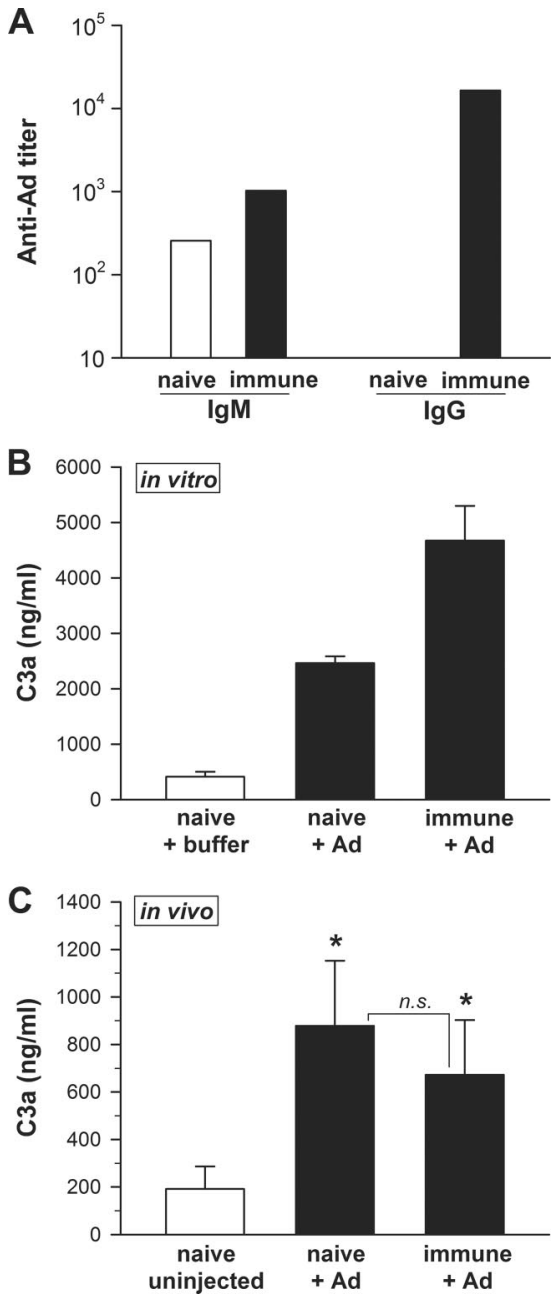

FIG. 3. Immunizing against Ad augments complement activation in vitro, but not in vivo. (A) Mice were immunized intramuscularly with $1.0 \times 10^{10} \mathrm{vp}$ of the Ad vector. Two weeks later, the titers of Adspecific IgM and IgG were assayed by ELISA. Anti-Ad antibody levels were measured for four naïve mice (open bars) and four immunized mice (black bars). In naïve mice, Ad-specific IgG was below the limit of detection (titer of $<6$ ). (B) Plasma from naïve or immunized mice was mixed with Ad vector, and the level of $\mathrm{C} 3 \mathrm{a}$ was measured after 90 min as before. Results for each group are the means from four individual plasma samples. Results for each group were significantly different from those for every other group, with a $P$ value of $\leq 0.05$ (Holm-Sidak post hoc). An independent experiment yielded similar results. (C) Naïve or immunized mice (four mice per group) were injected i.v. with $1.0 \times 10^{12} \mathrm{vp} / \mathrm{kg}$ of the Ad vector, and plasma was collected at $30 \mathrm{~min}$ for a C3a ELISA. *, $P$ value of $\leq 0.05$ versus uninjected mice (Holm-Sidak post hoc); n.s., not significant.

shown that Ad-specific antibodies are able to enhance complement activation by Ad $(9,67)$. To further explore the role of antibodies, we immunized mice by intramuscular injection with Ad. This led to an increase in anti-Ad IgG titers from undetectable levels in naïve mice to a titer of 16,384 in immunized mice (Fig. 3A). Naïve mice have natural IgM antibodies that can recognize Ad (66), and we found that immunization caused only a modest rise in the amount of IgM that could bind to Ad, from a titer of 256 for naïve mice to 1,024 for immunized mice (Fig. 3A). As expected, Ad was able to induce significantly 


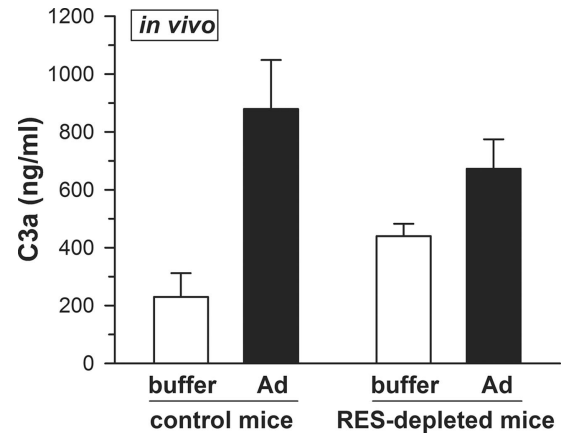

FIG. 4. Activation of complement by Ad is partially dependent on the RES. Mice were injected i.v. with either PBS (control) or clodronate liposomes (RES depleted). One day later, mice (four to seven per group) were injected i.v. with buffer or $1.0 \times 10^{12} \mathrm{vp} / \mathrm{kg}$ of Ad vector. Plasma was collected at $30 \mathrm{~min}$ for C3a ELISA. Results for all groups were significantly different from those of every other group $(P \leq 0.05$, Holm-Sidak post hoc test). In control mice, Ad increased C3a levels to $649 \mathrm{ng} / \mathrm{ml}$ above the baseline. In RES-depleted mice, the corresponding difference between results for buffer and Ad was only $232 \mathrm{ng} / \mathrm{ml}$.

more C3a when Ad was incubated with plasma from immunized mice than from naïve mice (Fig. $3 \mathrm{~B}$ ). This result confirms the important role of antibodies in vitro, whether the antibodies are natural or induced. However, when immunized mice were injected i.v. with Ad, complement activation was not significantly different than that measured for naïve mice (Fig. 3C). Thus, we were unable to detect any essential role for antibodies in vivo, even in Ad-immune mice.

Role of the RES and viral entry. Particulate materials are rapidly cleared from the circulation by a collection of mononuclear phagocytes known as the reticuloendothelial system (RES). The RES cells that clear Ad from the circulation consist of KCs in the liver and macrophages in the spleen (68). We have previously shown that i.v. injection of Ad rapidly kills KCs at doses of $\geq 1.0 \times 10^{11} \mathrm{vp} / \mathrm{kg}$, but not at a dose of $1.0 \times 10^{10}$ $\mathrm{vp} / \mathrm{kg}$ (39). Interestingly, the complement response to Ad has the same dose threshold, $1.0 \times 10^{11} \mathrm{vp} / \mathrm{kg}$ (Fig. 1B). To test whether the RES contributes to the induction of complement by Ad, we preinjected mice i.v. with clodronate liposomes to deplete RES macrophages. We found, unexpectedly, that RES depletion itself caused a significant increase in C3a levels (Fig. 4). In spite of this shift in the baseline, we were still able to detect a modest but statistically significant decrease in the ability of Ad to induce complement activation in RES-depleted mice compared to Ad-injected control mice (Fig. 4). Thus, the RES may contribute to the ability of Ad to activate complement in vivo. However, the RES is not absolutely required, because injecting Ad into RES-depleted mice still caused a statistically significant increase in C3a production (Fig. 4). We also examined the complement response in splenectomized mice, but we found that splenectomized mice mounted a robust C3a response to Ad that was not significantly different than that in control mice (data not shown). In summary, it appears that the RES modestly influences the complement response to $\mathrm{Ad}$, but other factors also play a role.

We have previously used the entry-deficient mutant virus ts 1 to differentiate between the effects of the capsid and the effects of viral entry (59). The $t s 1$ mutant contains a mutation in the Ad protease, and when the $t s 1$ mutant is grown at the nonper-
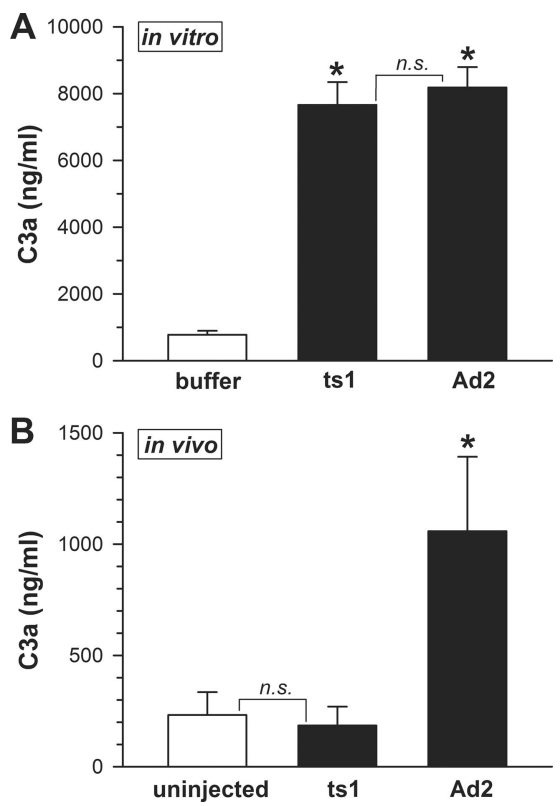

FIG. 5. Entry-deficient mutant virus $t s 1$ induces normal activation of complement in vitro but is unable to activate complement in vivo. (A) Mouse plasma was incubated in vitro with buffer, the $t s 1$ mutant, or Ad2. Levels of C3a were measured after $90 \mathrm{~min}$. An independent experiment produced similar results. *, $P$ value of $\leq 0.05$ versus buffer (Holm-Sidak post hoc). (B) C57BL/6 mice (four per group) were injected i.v. with viruses at a dose of $1.0 \times 10^{12} \mathrm{vp} / \mathrm{kg}$, and plasma was collected 30 min later for C3a ELISA. *, $P$ value of $\leq 0.05$ versus all other groups (Holm-Sidak post hoc); n.s., not significant.

missive temperature of $39^{\circ} \mathrm{C}$, the resulting virions are permanently arrested in an immature state (16). The $t s 1$ mutant is able to complete the initial steps of cellular binding and endocytosis, but $t s 1$ virion disassembly is abnormal (17). $t s 1$ virions are unable to release the membrane-lytic protein VI; therefore, $t s 1$ virions are unable to escape from endosomes (64). We have shown that KCs in the mouse liver accumulate the $t s 1$ mutant to the same extent that they accumulate wild-type Ad; nevertheless, the $t s 1$ mutant is unable to kill KCs (59). Since the $t s 1$ mutant is derived from $\mathrm{Ad} 2$, we used wild-type $\mathrm{Ad} 2$ as a control in all experiments with the $t s 1$ mutant.

There are no known structural differences between the external surfaces of $t s 1$ and Ad2 capsids; therefore, we predicted that the ts 1 mutant would be able to activate complement normally in vitro. Indeed, $\mathrm{Ad} 2$ and the $t s 1$ mutant caused similar elevations of $\mathrm{C} 3 \mathrm{a}$ when they were mixed with mouse plasma in vitro (Fig. 5A). Remarkably, however, the $t s 1$ mutant was unable to activate complement when injected into mice (Fig. 5B). This finding demonstrates that although the Ad capsid is sufficient on its own to activate complement in vitro, direct complement activation by the capsid is of negligible importance in vivo. Rather, complement activation in vivo depends on the ability of Ad virions to traffic normally within cells.

Certain modifications to the Ad5 fiber shaft are known to reduce the efficiency of viral transduction and cause partial defects in intracellular trafficking $(35,60)$. To obtain further evidence for the importance of virion trafficking in activating complement, we tested two of these fiber-modified vectors for 


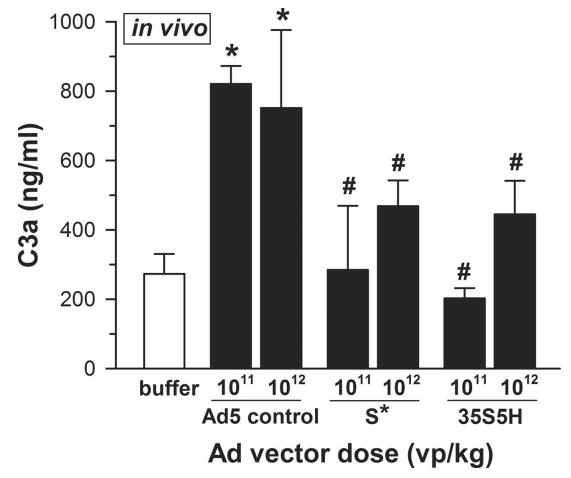

FIG. 6. Poor complement induction in vivo by fiber-altered Ad5 vectors with known defects in cell transduction ability. $\mathrm{S}^{*}$ contains a four-residue substitution in the third beta-repeat of the fiber shaft. In $35 \mathrm{~S} 5 \mathrm{H}$, the Ad5 fiber shaft has been replaced with the shorter Ad35 fiber shaft. The control Ad5 vector was Av1nBg. Mice (four per group) were injected with Ad vector at doses of $1.0 \times 10^{11}$ or $1.0 \times 10^{12} \mathrm{vp} / \mathrm{kg}$, and plasma was collected at $30 \mathrm{~min}$ for C3a ELISA. *, $P$ value of $\leq 0.05$ versus buffer-injected mice; \#, $P$ value of $\leq 0.05$ versus the same dose of the Ad5 control vector (Holm-Sidak post hoc).

their ability to activate complement in mice. $\mathrm{S}^{*}$ is an $\mathrm{Ad} 5$ vector that has been altered only in four residues of the fiber shaft (60), and this alteration has a negative impact on both intracellular trafficking and liver transduction $(35,60) .35 \mathrm{~S} 5 \mathrm{H}$ is an Ad5 vector where the type 5 fiber shaft has been replaced with the much shorter Ad35 fiber shaft, leaving the type 5 fiber head in place (60). $35 \mathrm{~S} 5 \mathrm{H}$ is impaired in transduction both in vitro and in vivo (60). We have shown that following an i.v. injection, these mutant vectors are accumulated by $\mathrm{KCs}$ in amounts that are indistinguishable from the amount of the control Ad5 vector within KCs (59). However, $\mathrm{S}^{*}$ and $35 \mathrm{~S} 5 \mathrm{H}$ are much less cytotoxic than the control Ad5 vector, causing significantly less $\mathrm{KC}$ death at a dose of $1.0 \times 10^{12} \mathrm{vp} / \mathrm{kg}$ and no detectable KC death at a dose of $1.0 \times 10^{11} \mathrm{vp} / \mathrm{kg}(59)$. When we examined $\mathrm{C} 3$ a levels after an i.v. injection of $\mathrm{S}^{*}$ and $35 \mathrm{~S} 5 \mathrm{H}$, we found that both of these mutant vectors induced significantly less complement activation than did the control Ad vector, regardless of dose (Fig. 6). C3a levels at the dose of $1.0 \times 10^{12} \mathrm{vp} / \mathrm{kg}$ of $\mathrm{S}^{*}$ and $35 \mathrm{~S} 5 \mathrm{H}$ appeared to be moderately elevated above the baseline, although these levels did not reach statistical significance (Fig. 6). Thus, fiber-modified Ad5 vectors with deficiencies in transduction and $\mathrm{KC}$ killing have greatly reduced abilities to activate complement in vivo.

Complement generation in mice after a very high Ad dose. Although the dose response experiment in Fig. 1B showed robust complement activation after i.v. Ad doses of $1.0 \times 10^{11}$ and $1.0 \times 10^{12} \mathrm{vp} / \mathrm{kg}$, complement activation was even greater after a dose of $1.0 \times 10^{13} \mathrm{vp} / \mathrm{kg}$ (Fig. 1B). This result suggested the possibility that additional mechanisms might come into play following i.v. injection of very high Ad doses. We therefore injected mice at a dose of $1.0 \times 10^{13} \mathrm{vp} / \mathrm{kg}$ and examined whether complement activation still remained dependent on viral trafficking. We also examined the relative contributions of classical and nonclassical pathways.

We found that the $t s 1$ mutant did not activate complement at any dose (Fig. 7A). This result confirms the idea that direct capsid-mediated activation of complement does not measurably contribute to plasma C3a levels in vivo, in spite of the fact
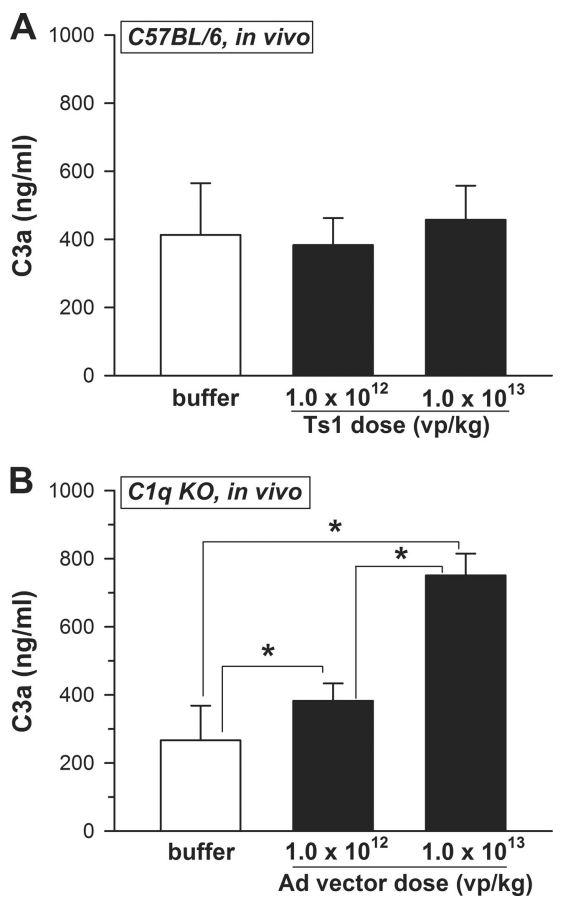

FIG. 7. A very high dose of Ad induces complement through the same mechanisms as a lower dose. (A) The $t s 1$ mutant was unable to induce $\mathrm{C} 3 \mathrm{a}$ in vivo at any dose, indicating that direct activation of complement by Ad capsids is a relatively unimportant mechanism in vivo. Results are for three to five C57BL/6 mice per group at $30 \mathrm{~min}$ postinjection. Nonsignificant $P$ value of $>0.05$ (ANOVA). (B) Injection of $\mathrm{C} 1 \mathrm{q} \mathrm{KO}$ mice (four or five per group) i.v. with an Ad5 vector led to dose-dependent complement activation, indicating a significant contribution of nonclassical pathways. Plasma was collected $30 \mathrm{~min}$ after injection. *, $P$ value of $\leq 0.05$ (Holm-Sidak post hoc).

that this is such an important mechanism for in vitro complement activation (Fig. 5A). It also demonstrates that complement activation in vivo is critically dependent on the ability of Ad to traffic normally within cells.

When we examined complement activation in $\mathrm{C} 1 \mathrm{q} \mathrm{KO}$ mice that lack the classical pathway, we found that Ad5 vector at a dose of $1.0 \times 10^{13} \mathrm{vp} / \mathrm{kg}$ induced even more complement activation than a dose of $1.0 \times 10^{12} \mathrm{vp} / \mathrm{kg}$, indicating a major dose-dependent role for nonclassical complement activation pathways (Fig. 7B).

PEGylation of Ad blocks complement activation. Conjugating proteins with PEG or other inert polymers is a widely used strategy to decrease protein-protein interaction, and PEGylation of Ad has been shown to reduce the ability of antibodies to bind Ad (12). Thus, given our finding that natural antibodies play a vital role in complement activation in vitro (Fig. 2B), we expected that PEGylated Ad would be a poor complement activator in vitro. However, we were unsure whether PEGylation would have any protective effect in vivo, where complement is activated through quite different mechanisms. In mouse studies, it has been shown that coating Ad with PEG or other polymers has beneficial effects in decreasing innate toxicity and increasing the ability of Ad to persist in the circulation $(11,18,23,40)$.

We PEGylated Ad and verified that it remained able to transduce the liver (Fig. 8A), in agreement with previous re- 

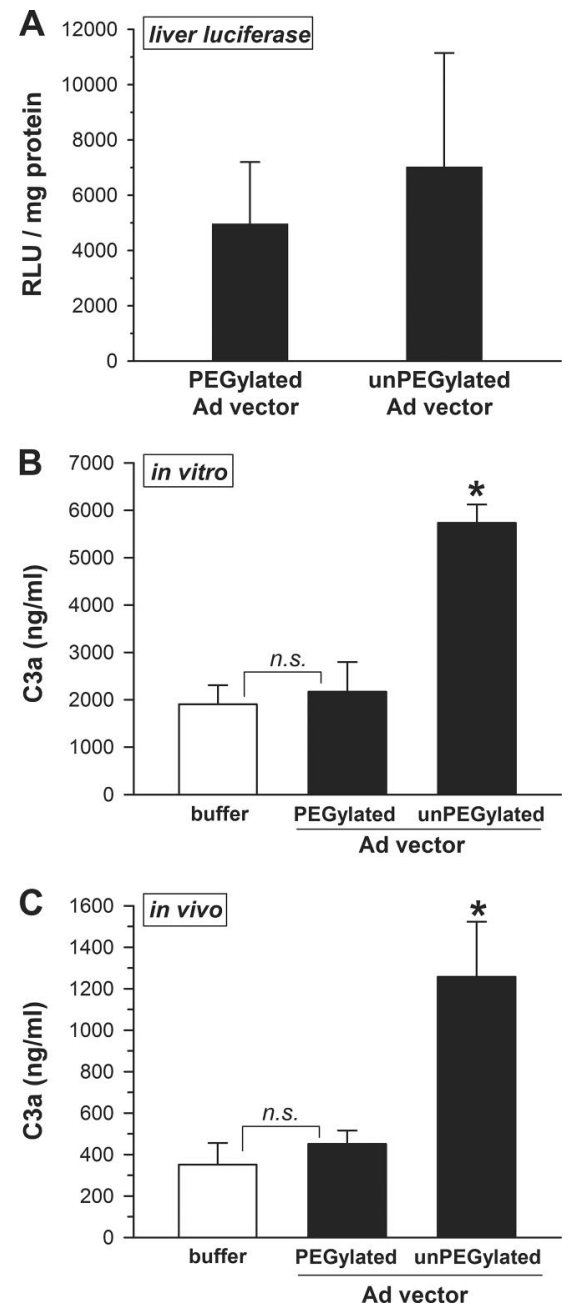

FIG. 8. PEGylating Ad reduces complement activation in vivo while leaving liver transduction intact. (A) PEGylated Ad remained able to transduce the liver. Mice (four per group) were injected i.v. with $1.0 \times 10^{12} \mathrm{vp} / \mathrm{kg}$ of an unPEGylated or PEGylated luciferaseexpressing vector. After $48 \mathrm{~h}$, luciferase activity was measured in liver homogenates. Nonsignificant $P$ value of $>0.05$ ( $t$ test). No luciferase activity was detected in uninjected control mice (not shown). (B) PEGylation blocked the ability of Ad to activate complement in vitro. Mouse plasma (three samples per group) was mixed with Ad, and after $90 \mathrm{~min}$, the level of C3a was measured as before. An independent experiment yielded similar results. *, $P$ value of $\leq 0.05$ versus all other groups (Holm-Sidak post hoc); n.s., not significant. (C) PEGylation blocked the ability of Ad to activate complement in vivo. Mice (four to seven per group) were injected i.v. with $1.0 \times 10^{12} \mathrm{vp} / \mathrm{kg}$, and plasma was collected at $30 \mathrm{~min}$ for $\mathrm{C} 3 \mathrm{a}$ measurement. An independent experiment yielded similar results. *, $P$ value of $\leq 0.05$ versus all other groups (Holm-Sidak post hoc); n.s., not significant.

sults (40). When we measured C3a generation, we found that PEGylation blocked the ability of Ad to activate complement in vitro, as predicted (Fig. 8B). More interestingly, PEGylated Ad did not detectably activate complement in vivo (Fig. 8C). Thus, even though Ad activates complement through markedly different mechanisms in vitro and in vivo, PEGylation had a beneficial effect in attenuating complement activation in both situations.

\section{DISCUSSION}

Although previous studies have shown an important functional role for complement in the innate response to Ad, until now it has been unclear whether complement activation by Ad can be quantitated in vivo or how Ad activates the complement system. The complement system has an innate ability to recognize many microbes directly, and Ad is no exception. Our most surprising finding was that this type of direct recognition of virions is not a major mechanism for complement activation by Ad in vivo. In vivo experiments with the $t s 1$ mutant showed that the complement system primarily senses the effects of Ad on cells rather than detecting the virions themselves (Fig. 9).

Limitations of modeling complement activation in vitro. At first glance, mixing Ad with mouse plasma in vitro would seem to be a suitable model for i.v. injection of Ad. Both in vitro and in vivo, Ad immediately comes into direct contact with complement and other plasma proteins. It has been assumed that Ad virions interact with these plasma proteins in vivo in much the same manner that they do in vitro. However, our results show that this is not the case.

There are likely to be a number of contributing factors that explain why mixing Ad with plasma is not a realistic in vitro model system. First, in the in vitro system, Ad is kept in contact with plasma proteins for a lengthy time, but after an i.v. injection, Ad is cleared from the circulation within minutes $(1,18)$, depriving virions of direct contact with plasma proteins. Second, there are no cells in the in vitro system, leading to a lack of cell-associated complement regulatory proteins, such as Crry and decay-accelerating factor (32). Finally, Ad causes rapid cytotoxic damage to cells after an i.v. injection $(39,59)$, but this damage is absent from the in vitro system. As explained in more detail below, dead and dying cells are powerful complement activators, and we propose that cell damage caused by Ad vectors is likely to be an important complement inducer in vivo.

Our in vitro results with mouse plasma are in general agreement with previous studies with human plasma that show that Ad activates complement through antibodies and the classical pathway $(9,49,67)$, although the role of natural antibodies in human plasma has not been examined. Some studies indicate that Ad can cause consumption of alternative pathway components in human plasma $(29,49)$. This might be due to the fact that the classical pathway, through its activation of $\mathrm{C} 3$, can stimulate the alternative pathway amplification loop $(19,49)$. In the current study, we showed that antibodies and the classical pathway are both required for Ad to initiate complement activation in vitro, and we found no evidence that Ad initiates complement activation through other mechanisms in mouse plasma. Our in vivo studies yielded quite different results, however, which seriously undermine the relevance of these types of in vitro experiments.

Complement activation by Ad in vivo. In vivo experiments with the $t s 1$ mutant showed no activation of complement even though ts 1 virions were fully able to activate complement in vitro. This provided a striking demonstration that the initial trigger for complement activation in vivo is completely different than that in vitro. Because the $t s 1$ mutant is defective at trafficking inside cells, we conclude that complement activation in vivo is triggered primarily through interaction of Ad with 
In vitro

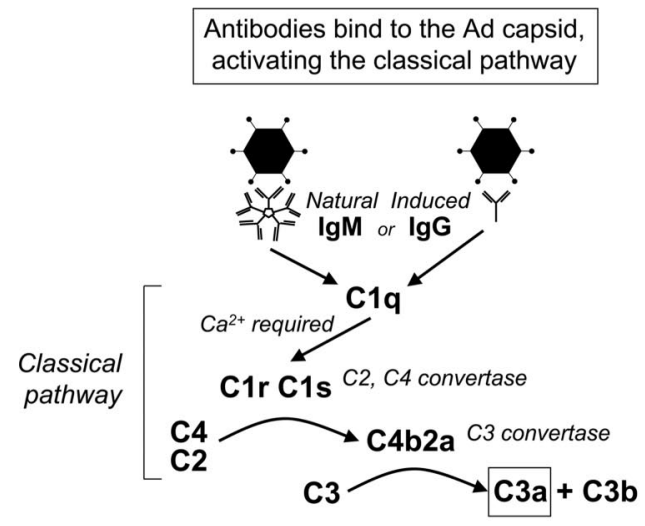

In vivo

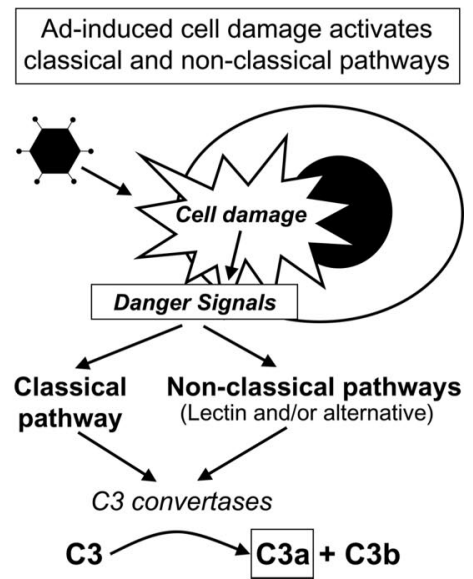

FIG. 9. Proposed mechanisms for Ad-induced complement activation. In vitro, the initial step is binding of antibody to Ad. These antibodies can be either natural antibodies that have a native ability to recognize the viral capsid or specific anti-Ad antibodies from immunized mice. C1q is then able to bind to the antibodies and activate the classical pathway. In vivo, however, this mechanism makes a negligible contribution to C3a levels. Instead, Ad damages cells during entry, thereby exposing complement-activating danger signals. These danger signals may include disrupted cellular membranes and exposed chromatin that are induced within $10 \mathrm{~min}$ after an i.v. Ad injection (39). Disrupted cellular membranes and chromatin are well-established danger signals that have been shown to activate complement $(22,28,47,48)$.

cells and not through any ability of the virions themselves to activate complement. Although it is entirely plausible that there may be a minor amount of direct complement activation by Ad virions in vivo, results with the $t s 1$ mutant show that this mechanism does not make any measureable contribution to plasma C3a levels.

Complement is known to be activated by both exogenous microbial stimuli and endogenous (self- or altered self-) stimuli. One likely initiation signal for complement after i.v. injection of Ad is cellular damage, which is a potent complement activator (14). Damaged, dying, and dead cells are well-established endogenous "danger" signals that activate both the complement system and other types of innate responses (27, 33, 34). Complement can be activated by both apoptotic and necrotic cells, but it is generally observed that necrotic cells activate complement more effectively (14).

Our previous studies of the liver found that i.v. Ad causes necrosis of KCs within 10 min, with KCs becoming permeable to propidium iodide and trypan blue at Ad doses as low as $1.0 \times 10^{11} \mathrm{vp} / \mathrm{kg}(39,59)$. Likewise, i.v. Ad at the same doses causes a rapid increase in serum levels of the cytoplasmic enzyme lactate dehydrogenase, confirming that Ad disrupts cellular plasma membrane integrity in vivo (39). The mechanism for rapid Ad-induced cell damage is unknown, but we recently reported that the $t s 1$ mutant is unable to kill $\mathrm{KCs}$ in vivo, indicating that cell damage is dependent on virion trafficking (59). We speculate that the $t s 1$ mutant may be unable to kill cells because of its inability to release the membrane-lytic Ad protein VI (64). Our finding in the current study that the ts 1 mutant does not detectably activate complement in vivo supports the hypothesis that Ad-induced cell damage is responsible for activating the complement system. Likewise, fiber-modified Ad vectors, such as $\mathrm{S}^{*}$ and $35 \mathrm{~S} 5 \mathrm{H}$, have a reduced ability to kill KCs (59), which correlates with the significant attenuation of complement activation reported in the current study. Although our major focus in past studies has been on the RES, it is important to emphasize our finding in the current study that Ad remains able to activate complement in RES-depleted mice, albeit to a reduced extent. This finding indicates that Ad may act on both RES and non-RES cell types to induce complement activation.

Regarding pathways, it has been shown that damaged cells can stimulate all three of the complement pathways: the classical $(14,22,44,48,51)$, lectin $(28,43)$, and alternative $(65)$ pathways. Consistent with this observation, our in vivo studies found that both classical and nonclassical pathways participate in activation of complement by Ad. Further work will be needed to determine whether Ad-induced nonclassical activation is due to the lectin or alternative pathway or both of these. A recent study from Appledorn et al. (3) also provides evidence for the involvement of multiple complement activation pathways in the innate response to $\mathrm{Ad}$. $\mathrm{C} 3 \mathrm{KO}$ mice that are deficient in all three complement pathways have reduced cytokine responses to $\mathrm{Ad}$, but deficiencies in individual complement pathways have little effect on Ad induction of cytokines (3).

Numerous studies have shown that the complement system is attuned to endogenous danger signals that become exposed during cell damage or death. For example, two lipids that are normally present mainly in the inner leaflet of the plasma membrane, phosphatidylserine and phosphatidylethanolamine, become exposed on the outer leaflet of the plasma membranes of dying and dead cells. Phosphatidylserine is recognized directly by $\mathrm{C} 1 \mathrm{q}$ (47), which can then activate the classical pathway. Phosphatidylethanolamine is recognized by serum amyloid protein (SAP) (13), and SAP can in turn bind C1q and activate the classical pathway. It seems likely that these inner leaflet phospholipids are exposed in vivo after Ad injection, because we have shown that Ad disrupts the plasma membrane of KCs (39). Similarly, cellular DNA is another danger signal that becomes exposed during both apoptosis and necrosis (26) and activates complement $(22,28,48)$. We have noted that 
Ad-induced KC death is associated with the rapid disruption and degradation of chromatin (39). It is not yet clear which of these danger signals might be most important for complement activation in vivo, but it would not be surprising to find that Ad-induced cellular damage results in the exposure of multiple danger signals that activate complement through multiple routes.

Overall, a number of key findings in the current study and in our previous work point to the likelihood that Ad-induced cell damage and cell death are important signals for the activation of complement. (i) Ad has been shown to cause cell damage in vivo at the same vector doses and with the same kinetics with which complement was activated in the current study $(39,59)$. (ii) Damaged, dying, and dead cells are known to present danger signals that are powerful activators of multiple complement pathways (14). We have shown that certain of these danger signals (disrupted cellular membranes, exposed chromatin) are rapidly induced after the i.v. injection of Ad (39). (iii) Ad-induced cell death is particularly noticeable in the RES (39), and depletion of the RES in the current study partially reduced the complement response to Ad. (iv) Ad viruses or vectors that are unable to kill cells or have reduced cell killing ability (59) were found in the current study to be poor complement activators in vivo.

Prospects for attenuating the Ad-induced complement response. Our results illustrate two potential approaches to decrease the complement response to Ad vectors: mutating the vector and PEGylating the vector. We found that changing the fiber shaft greatly reduced the complement response. Unfortunately, however, these changes also make these vectors much less efficient at transducing cells $(35,60)$. Because our experiments with the $t s 1$ mutant showed that trafficking of virions within cells is essential for complement activation in vivo, it seems likely that the impaired transduction abilities of $\mathrm{S}^{*}$ and $35 \mathrm{~S} 5 \mathrm{H}$ contribute to their reduced ability to activate complement. It will be interesting to explore whether other types of mutations might yield Ad vectors that induce complement poorly in vivo while still retaining their ability to transduce cells.

We also found that PEGylation was an effective method to decrease the complement response. Because PEG protects Ad from antibodies $(11,12)$, it is not surprising that PEGylation attenuated complement activation by Ad in vitro. Encouragingly, our in vivo experiments also found a decreased complement response to PEGylated Ad. PEGylation by the methods used here does not negatively impact the ability of Ad to transduce the liver, although it is important to point out that PEGylation may not be a good approach if the goal is to transduce other organs. For example, PEGylation detargets Ad from the peritoneum (24). It will require extensive further investigation to determine exactly how PEGylation attenuates the complement response in vivo. One possibility is that PEGylation might detarget certain cell types that are involved in the complement response while leaving hepatocyte transduction intact. In this regard, it has already been shown that PEGylation reduces the accumulation of Ad in KCs (40).

C3a as a marker of the innate response. Our study indicates that the plasma level of $\mathrm{C} 3 \mathrm{a}$ is an unusually sensitive measure of the early innate response to Ad. Although we examined only systemic administration of $\mathrm{Ad}$, it will also be interesting to explore whether $\mathrm{C} 3 \mathrm{a}$ levels rise after local administration of Ad vectors to tumors or other tissues. In addition, ELISAs are available for human $\mathrm{C} 3 \mathrm{a}$, and it should be possible to evaluate whether complement is activated in patients after the administration of Ad vectors. It remains to be determined whether $\mathrm{C} 3 \mathrm{a}$ itself has any important biological role in the innate response to Ad or whether it is best viewed as just a marker of complement activation. $\mathrm{C} 3 \mathrm{a}$ is a potent chemotactic factor and leukocyte activator in vitro (25), but its function in vivo is more complicated and includes both proinflammatory and protective effects (31).

In conclusion, Ad capsids are recognized by natural antibodies and stimulate the classical pathway in vitro, but this mechanism is of limited importance when Ad is injected i.v. in mice. Instead, Ad induces cellular signals that alert the complement system to danger. A deeper understanding of the signals and pathways involved in the activation of complement will suggest strategies to help Ad vectors escape the attention of the innate immune system. More broadly, it is worth considering the concept that in some cases, microbial-induced pathology may be a much more important driver of complement activation than the microbe itself.

\section{ACKNOWLEDGMENTS}

This research was supported by the FDA, including support from the Critical Path Program.

We thank Michael Diamond for providing mice and the CBER veterinary staff for their outstanding support. We thank Suzanne Epstein and Jakob Reiser for constructive comments on the manuscript.

\section{REFERENCES}

1. Alemany, R., K. Suzuki, and D. T. Curiel. 2000. Blood clearance rates of adenovirus type 5 in mice. J. Gen. Virol. 81:2605-2609.

2. Appledorn, D. M., A. Kiang, A. McBride, H. Jiang, S. Seregin, J. M. Scott, R. Stringer, Y. Kousa, M. Hoban, M. M. Frank, and A. Amalfitano. 2008. Wild-type adenoviruses from groups A-F evoke unique innate immune responses, of which HAd3 and SAd23 are partially complement dependent. Gene Ther. 15:885-901.

3. Appledorn, D. M., A. McBride, S. Seregin, J. M. Scott, N. Schuldt, A. Kiang, S. Godbehere, and A. Amalfitano. 2008. Complex interactions with several arms of the complement system dictate innate and humoral immunity to adenoviral vectors. Gene Ther. 15:1606-1617.

4. Appledorn, D. M., S. Patial, A. McBride, S. Godbehere, N. van Rooijen, N. Parameswaran, and A. Amalfitano. 2008. Adenovirus vector-induced innate inflammatory mediators, MAPK signaling, as well as adaptive immune responses are dependent upon both TLR2 and TLR9 in vivo. J. Immunol. 181:2134-2144.

5. Botto, M., C. Dell'Agnola, A. E. Bygrave, E. M. Thompson, H. T. Cook, F. Petry, M. Loos, P. P. Pandolfi, and M. J. Walport. 1998. Homozygous C1q deficiency causes glomerulonephritis associated with multiple apoptotic bodies. Nat. Genet. 19:56-59.

6. Brunetti-Pierri, N., D. J. Palmer, V. Mane, M. Finegold, A. L. Beaudet, and P. Ng. 2005. Increased hepatic transduction with reduced systemic dissemination and proinflammatory cytokines following hydrodynamic injection of helper-dependent adenoviral vectors. Mol. Ther. 12:99-106.

7. Carlisle, R. C., Y. Di, A. M. Cerny, A. F. Sonnen, R. B. Sim, N. K. Green, V. Subr, K. Ulbrich, R. J. Gilbert, K. D. Fisher, R. W. Finberg, and L. W. Seymour. 2009. Human erythrocytes bind and inactivate type 5 adenovirus by presenting Coxsackie virus-adenovirus receptor and complement receptor 1 . Blood 113:1909-1918.

8. Cerullo, V., M. P. Seiler, V. Mane, N. Brunetti-Pierri, C. Clarke, T. K. Bertin, J. R. Rodgers, and B. Lee. 2007. Toll-like receptor 9 triggers an innate immune response to helper-dependent adenoviral vectors. Mol. Ther. 15:378-385.

9. Cichon, G., S. Boeckh-Herwig, H. H. Schmidt, E. Wehnes, T. Muller, P. Pring-Akerblom, and R. Burger. 2001. Complement activation by recombinant adenoviruses. Gene Ther. 8:1794-1800.

10. Cotter, M. J., A. K. Zaiss, and D. A. Muruve. 2005. Neutrophils interact with adenovirus vectors via Fc receptors and complement receptor 1. J. Virol. 79:14622-14631. 
11. Croyle, M. A., N. Chirmule, Y. Zhang, and J. M. Wilson. 2001. "Stealth" adenoviruses blunt cell-mediated and humoral immune responses against the virus and allow for significant gene expression upon readministration in the lung. J. Virol. 75:4792-4801.

12. Croyle, M. A., Q. C. Yu, and J. M. Wilson. 2000. Development of a rapid method for the PEGylation of adenoviruses with enhanced transduction and improved stability under harsh storage conditions. Hum. Gene Ther. 11: 1713-1722.

13. Familian, A., B. Zwart, H. G. Huisman, I. Rensink, D. Roem, P. L Hordijk, L. A. Aarden, and C. E. Hack. 2001. Chromatin-independent binding of serum amyloid P component to apoptotic cells. J. Immunol 167:647-654.

14. Gaipl, U. S., S. Kuenkele, R. E. Voll, T. D. Beyer, W. Kolowos, P. Heyder, J. R. Kalden, and M. Herrmann. 2001. Complement binding is an early feature of necrotic and a rather late event during apoptotic cell death. Cell Death Differ. 8:327-334.

15. Gewurz, H., S. C. Ying, H. Jiang, and T. F. Lint. 1993. Nonimmune activation of the classical complement pathway. Behring Inst. Mitt. 93:138-147.

16. Greber, U. F. 1998. Virus assembly and disassembly: the adenovirus cysteine protease as a trigger factor. Rev. Med. Virol. 8:213-222.

17. Greber, U. F., P. Webster, J. Weber, and A. Helenius. 1996. The role of the adenovirus protease in virus entry into cells. EMBO J. 15:1766-1777.

18. Green, N. K., C. W. Herbert, S. J. Hale, A. B. Hale, V. Mautner, R. Harkins, T. Hermiston, K. Ulbrich, K. D. Fisher, and L. W. Seymour. 2004. Extended plasma circulation time and decreased toxicity of polymer-coated adenovirus. Gene Ther. 11:1256-1263.

19. Harboe, M., and T. E. Mollnes. 2008. The alternative complement pathway revisited. J. Cell Mol. Med. 12:1074-1084.

20. Hartman, Z. C., D. M. Appledorn, and A. Amalfitano. 2008. Adenovirus vector induced innate immune responses: impact upon efficacy and toxicity in gene therapy and vaccine applications. Virus Res. 132:1-14.

21. Hartman, Z. C., D. M. Appledorn, D. Serra, O. Glass, T. B. Mendelson, T. M. Clay, and A. Amalfitano. 2008. Replication-attenuated human adenoviral type 4 vectors elicit capsid dependent enhanced innate immune responses that are partially dependent upon interactions with the complement system. Virology 374:453-467.

22. Hicks, P. S., L. Saunero-Nava, T. W. Du Clos, and C. Mold. 1992. Serum amyloid $\mathrm{P}$ component binds to histones and activates the classical complement pathway. J. Immunol. 149:3689-3694.

23. Hofherr, S. E., H. Mok, F. C. Gushiken, J. A. Lopez, and M. A. Barry. 2007. Polyethylene glycol modification of adenovirus reduces platelet activation, endothelial cell activation, and thrombocytopenia. Hum. Gene Ther. 18:837848.

24. Hofherr, S. E., E. V. Shashkova, E. A. Weaver, R. Khare, and M. A. Barry. 2008. Modification of adenoviral vectors with polyethylene glycol modulates in vivo tissue tropism and gene expression. Mol. Ther. 16:1276-1282.

25. Hugli, T. E. 1990. Structure and function of C3a anaphylatoxin. Curr. Top. Microbiol. Immunol. 153:181-208.

26. Jahr, S., H. Hentze, S. Englisch, D. Hardt, F. O. Fackelmayer, R. D. Hesch, and R. Knippers. 2001. DNA fragments in the blood plasma of cancer patients: quantitations and evidence for their origin from apoptotic and necrotic cells. Cancer Res. 61:1659-1665.

27. Jeannin, P., S. Jaillon, and Y. Delneste. 2008. Pattern recognition receptors in the immune response against dying cells. Curr. Opin. Immunol. 20:530537.

28. Jensen, M. L., C. Honore, T. Hummelshoj, B. E. Hansen, H. O. Madsen, and P. Garred. 2007. Ficolin-2 recognizes DNA and participates in the clearance of dying host cells. Mol. Immunol. 44:856-865.

29. Jiang, H., Z. Wang, D. Serra, M. M. Frank, and A. Amalfitano. 2004 Recombinant adenovirus vectors activate the alternative complement pathway, leading to the binding of human complement protein $\mathrm{C} 3$ independent of anti-Ad antibodies. Mol. Ther. 10:1140-1142.

30. Kiang, A., Z. C. Hartman, R. S. Everett, D. Serra, H. Jiang, M. M. Frank, and A. Amalfitano. 2006. Multiple innate inflammatory responses induced after systemic adenovirus vector delivery depend on a functional complement system. Mol. Ther. 14:588-598.

31. Kildsgaard, J., T. J. Hollmann, K. W. Matthews, K. Bian, F. Murad, and R. A. Wetsel. 2000. Cutting edge: targeted disruption of the C3a receptor gene demonstrates a novel protective anti-inflammatory role for $\mathrm{C} 3 \mathrm{a}$ in endotoxin-shock. J. Immunol. 165:5406-5409.

32. Kim, D. D., and W. C. Song. 2006. Membrane complement regulatory proteins. Clin. Immunol. 118:127-136.

33. Kohl, J. 2006. The role of complement in danger sensing and transmission. Immunol. Res. 34:157-176.

34. Kono, H., and K. L. Rock. 2008. How dying cells alert the immune system to danger. Nat. Rev. Immunol. 8:279-289.

35. Kritz, A. B., C. G. Nicol, K. L. Dishart, R. Nelson, S. Holbeck, D. J. Von Seggern, L. M. Work, J. H. McVey, S. A. Nicklin, and A. H. Baker. 2007. Adenovirus 5 fibers mutated at the putative HSPG-binding site show restricted retargeting with targeting peptides in the HI loop. Mol. Ther. 15: 741-749.
36. Lambris, J. D., D. Ricklin, and B. V. Geisbrecht. 2008. Complement evasion by human pathogens. Nat. Rev. Microbiol. 6:132-142.

37. Lieber, A., C. Y. He, L. Meuse, D. Schowalter, I. Kirillova, B. Winther, and M. A. Kay. 1997. The role of Kupffer cell activation and viral gene expression in early liver toxicity after infusion of recombinant adenovirus vectors. J. Virol. 71:8798-8807.

38. Machemer, T., H. Engler, V. Tsai, S. Lee, S. Cannon-Carlson, M. Voloch, T. Schluep, S. Ravindran, G. Vellekamp, E. Brin, D. Cornell, S. Sutjipto, S. F. Wen, M. Horn, N. van Rooijen, D. Maneval, B. Hutchins, and D. LaFace. 2005. Characterization of hemodynamic events following intravascular infusion of recombinant adenovirus reveals possible solutions for mitigating cardiovascular responses. Mol. Ther. 12:254-263.

39. Manickan, E., J. S. Smith, J. Tian, T. L. Eggerman, J. N. Lozier, J. Muller, and A. P. Byrnes. 2006. Rapid Kupffer cell death after intravenous injection of adenovirus vectors. Mol. Ther. 13:108-117.

40. Mok, H., D. J. Palmer, P. Ng, and M. A. Barry. 2005. Evaluation of polyethylene glycol modification of first-generation and helper-dependent adenoviral vectors to reduce innate immune responses. Mol. Ther 11:66-79.

41. Mombaerts, P., J. Iacomini, R. S. Johnson, K. Herrup, S. Tonegawa, and V. E. Papaioannou. 1992. RAG-1-deficient mice have no mature B and T lymphocytes. Cell 68:869-877.

42. Muruve, D. A., V. Petrilli, A. K. Zaiss, L. R. White, S. A. Clark, P. J. Ross, R. J. Parks, and J. Tschopp. 2008. The inflammasome recognizes cytosolic microbial and host DNA and triggers an innate immune response. Nature 452:103-107.

43. Nauta, A. J., N. Raaschou-Jensen, A. Roos, M. R. Daha, H. O. Madsen, M. C. Borrias-Essers, L. P. Ryder, C. Koch, and P. Garred. 2003. Mannose-binding lectin engagement with late apoptotic and necrotic cells. Eur. J. Immunol. 33:2853-2863.

44. Nauta, A. J., L. A. Trouw, M. R. Daha, O. Tijsma, R. Nieuwland, W. J. Schwaeble, A. R. Gingras, A. Mantovani, E. C. Hack, and A. Roos. 2002. Direct binding of $\mathrm{C} 1 \mathrm{q}$ to apoptotic cells and cell blebs induces complement activation. Eur. J. Immunol. 32:1726-1736.

45. Nociari, M., O. Ocheretina, J. W. Schoggins, and E. Falck-Pedersen. 2007. Sensing infection by adenovirus: toll-like receptor-independent viral DNA recognition signals activation of the interferon regulatory factor 3 master regulator. J. Virol. 81:4145-4157.

46. Nunes, F. A., E. E. Furth, J. M. Wilson, and S. E. Raper. 1999. Gene transfer into the liver of nonhuman primates with E1-deleted recombinant adenoviral vectors: safety of readministration. Hum. Gene Ther. 10:2515-2526.

47. Paidassi, H., P. Tacnet-Delorme, V. Garlatti, C. Darnault, B. Ghebrehiwet, C. Gaboriaud, G. J. Arlaud, and P. Frachet. 2008. C1q binds phosphatidylserine and likely acts as a multiligand-bridging molecule in apoptotic cell recognition. J. Immunol. 180:2329-2338.

48. Paidassi, H., P. Tacnet-Delorme, T. Lunardi, G. J. Arlaud, N. M. Thielens, and P. Frachet. 2008. The lectin-like activity of human C1q and its implication in DNA and apoptotic cell recognition. FEBS Lett. 582: 3111-3116

49. Perreau, M., M. C. Guerin, C. Drouet, and E. J. Kremer. 2007. Interactions between human plasma components and a xenogenic adenovirus vector: reduced immunogenicity during gene transfer. Mol. Ther. 15: 1998-2007.

50. Pfeifer, P. H., M. S. Kawahara, and T. E. Hugli. 1999. Possible mechanism for in vitro complement activation in blood and plasma samples: Futhan/EDTA controls in vitro complement activation. Clin. Chem. 45: 1190-1199.

51. Pinckard, R. N., M. S. Olson, P. C. Giclas, R. Terry, J. T. Boyer, and R. A. O'Rourke. 1975. Consumption of classical complement components by heart subcellular membranes in vitro and in patients after acute myocardial infarction. J. Clin. Investig. 56:740-750.

52. Rambach, G., R. Wurzner, and C. Speth. 2008. Complement: an efficient sword of innate immunity. Contrib. Microbiol. 15:78-100.

53. Reid, T., R. Warren, and D. Kirn. 2002. Intravascular adenoviral agents in cancer patients: lessons from clinical trials. Cancer Gene Ther. 9:979986.

54. Schiedner, G., W. Bloch, S. Hertel, M. Johnston, A. Molojavyi, V. Dries, G. Varga, N. van Rooijen, and S. Kochanek. 2003. A hemodynamic response to intravenous adenovirus vector particles is caused by systemic Kupffer cell-mediated activation of endothelial cells. Hum. Gene Ther. 14:1631-1641.

55. Schnell, M. A., Y. Zhang, J. Tazelaar, G. P. Gao, Q. C. Yu, R. Qian, S. J. Chen, A. N. Varnavski, C. LeClair, S. E. Raper, and J. M. Wilson. 2001. Activation of innate immunity in nonhuman primates following intraportal administration of adenoviral vectors. Mol. Ther. 3:708-722.

56. Smith, J. S., J. Tian, J. N. Lozier, and A. P. Byrnes. 2004. Severe pulmonary pathology after intravenous administration of vectors in cirrhotic rats. Mol. Ther. 9:932-941.

57. Smith, J. S., J. Tian, J. Muller, and A. P. Byrnes. 2004. Unexpected pulmonary uptake of adenovirus vectors in animals with chronic liver disease. Gene Ther. 11:431-438.

58. Smith, J. S., Z. Xu, and A. P. Byrnes. 2008. A quantitative assay for mea- 
suring clearance of adenovirus vectors by Kupffer cells. J. Virol. Methods 147:54-60.

59. Smith, J. S., Z. Xu, J. Tian, S. C. Stevenson, and A. P. Byrnes. 2008 Interaction of systemically delivered adenovirus vectors with Kupffer cells in mouse liver. Hum. Gene Ther. 19:547-554.

60. Smith, T. A., N. Idamakanti, M. L. Rollence, J. Marshall-Neff, J. Kim, K. Mulgrew, G. R. Nemerow, M. Kaleko, and S. C. Stevenson. 2003. Adenovirus serotype 5 fiber shaft influences in vivo gene transfer in mice. Hum. Gene Ther. 14:777-787.

61. Tao, N., G. P. Gao, M. Parr, J. Johnston, T. Baradet, J. M. Wilson, J. Barsoum, and S. E. Fawell. 2001. Sequestration of adenoviral vector by Kupffer cells leads to a nonlinear dose response of transduction in liver. Mol. Ther. 3:28-35.

62. Tsai, V., R. Varghese, S. Ravindran, R. Ralston, and G. Vellekamp. 2008. Complement component $\mathrm{C} 1 \mathrm{q}$ and anti-hexon antibody mediate adenovirus infection of a CAR-negative cell line. Viral Immunol. 21:469-476.

63. van Rooijen, N., and A. Sanders. 1994. Liposome mediated depletion of macrophages: mechanism of action, preparation of liposomes and applications. J. Immunol. Methods 174:83-93.

64. Wiethoff, C. M., H. Wodrich, L. Gerace, and G. R. Nemerow. 2005. Adenovirus protein VI mediates membrane disruption following capsid disassembly. J. Virol. 79:1992-2000.
65. Xu, W., S. P. Berger, L. A. Trouw, H. C. de Boer, N. Schlagwein, C. Mutsaers, M. R. Daha, and C. van Kooten. 2008. Properdin binds to late apoptotic and necrotic cells independently of $\mathrm{C} 3 \mathrm{~b}$ and regulates alternative pathway complement activation. J. Immunol. 180:7613-7621.

66. Xu, Z., J. Tian, J. S. Smith, and A. P. Byrnes. 2008. Clearance of adenovirus by Kupffer cells is mediated by scavenger receptors, natural antibodies, and complement. J. Virol. 82:11705-11713.

67. Zaiss, A. K., M. J. Cotter, L. R. White, S. A. Clark, N. C. Wong, V. M. Holers, J. S. Bartlett, and D. A. Muruve. 2008. Complement is an essential component of the immune response to adeno-associated virus vectors. J. Virol. 82:2727-2740

68. Zhang, Y., N. Chirmule, G. P. Gao, R. Qian, M. Croyle, B. Joshi, J. Tazelaar, and J. M. Wilson. 2001. Acute cytokine response to systemic adenoviral vectors in mice is mediated by dendritic cells and macrophages. Mol. Ther. 3:697-707

69. Zhu, J., X. Huang, and Y. Yang. 2007. Innate immune response to adenoviral vectors is mediated by both Toll-like receptor-dependent and -independent pathways. J. Virol. 81:3170-3180.

70. Zinn, K. R., A. J. Szalai, A. Stargel, V. Krasnykh, and T. R. Chaudhuri. 2004 Bioluminescence imaging reveals a significant role for complement in liver transduction following intravenous delivery of adenovirus. Gene Ther. 11:1482-1486. 